\title{
RFID technology in the retail industry \\ - bound for success or failure? A two-factor approach
}

\section{Johanna Schönborn ${ }^{1}$}

\begin{abstract}
In this thesis, the adoption of Radio Frequency Identification (RFID) technology in the retail industry is analysed. Upon the review of substantial literature on technology adoption in the information management field, a two-factor model is established. This model incorporates enablers and inhibitors of RFID adoption, retrieved from reviewing supply chain management literature. The model is then tested in three expert interviews and based on the insights gained from those, a revised model is created which incorporates the main enablers and inhibitors as perceived by the experts. Additionally, an overview of the current status of the technology in the retail industry is given.
\end{abstract}

\section{Introduction}

When Walmart announced in 2003 that Radio Frequency Identification (RFID) tags would be fully implemented in its supply chain by 2005 , the expectations for the breakthrough of the new use of the technology skyrocketed (Hardgrave \& Miller, 2006). Other major retailers in the USA and Europe, such as TESCO and the METRO group, quickly followed. This triggered immense growth predictions for the spread of RFID among retailers, it was expected that soon the adoption of the technology would be a necessity for staying competitive within the industry. However, the pace of adoption ceased to live up to the expectations. The U.S. clothing retail industry was expected to be one of the fastest adopters, yet only four percent of the top 100 U.S. clothing retailers have fully adopted RFID in 2016 (Hardgrave \& Patton, 2016). In many other industries, similar trends have been observed. Despite the slow pace of adoption, the advantages of RFID are questioned little, for instance a 30-week trial showed that Walmart was able to reduce its out-of-stock items by $21 \%$ by using RFID tags (Hardgrave, Langford, Waller, \& Miller, 2008). Considering all the positive aspects of RFID technology and the great potential it entails, the question arises why relatively few retail companies have fully adopted the technology. Thus, the question on which the research will be built is:

\section{What are the implementation issues of RFID in the retail industry?}

Answering this question will further improve the understanding of the implementation process of RFID and of related technologies in general. Analysing positive and negative implementation issues is an important step towards understanding the situation that the technology is in. This includes, but is not limited to, finding and understanding the underlying problems of adoption, solving them and finally moving forward to make the spread of the technology live up to the expectations that were created more than a decade ago.

\footnotetext{
1 Johanna Schönborn received a BSc in Economics and Business Economics at Maastricht University in 2017. She currently works in sustainability and innovation in logistics at a German automotive company. Contact: j.schonborn@alumni.maastrichtuniversity.nl
} 
To find an answer to the above stated question, the technology itself will first be introduced. Then, the positive and negative sides to RFID will be shown by reviewing literature from the supply chain management field. Further, a review on technology adoption models in the information management literature will be provided. Building on both the supply chain and the information management perspective, a model will be proposed and tested with expert interviews. Based on the results of the interviews, a revised model will be presented. Finally, the results will be discussed in terms of their implications on research and practice.

\section{Literature Review}

\subsection{Introduction to RFID}

Although RFID is based on a technology that has been used since the Second World War as an identification method (Ton, Dessain, \& Stachowiak-Joulain, 2009), its relevance for improving supply chain management has only been investigated since the 1990's (Hardgrave \& Miller, 2006). In the subsequent decades, RFID received very limited attention until Walmart announced the implementation of the technology in 2003, as described above. In the retail industry it is mainly used to track inventory, but it is essentially the same technology that allows the driver of a modern car to open and start the car without taking the key out of his pocket (Ton et al., 2009). An RFID tag consists of a microchip, which stores information, and an antenna, which communicates the information to a reader (Angeles, 2004). As its name indicates, an RFID reader uses the radio waves transmitted by the tag to automatically identify the item that the tag is attached to, as well as to receive other information that may be stored on the tag (Delen, Hardgrave, \& Sharda, 2007). RFID tags can vary in terms of multiple attributes, one of which is the frequency they use to communicate. While low-frequency tags need to be closer to the reader to be identified than high-frequency ones, they are also much cheaper and require less energy (Angeles, 2004). As shown by Joshi (2000), a main requirement for optimizing any supply chain is the "availability of the right data at the right place and the right time in the right format". RFID technology attempts to provide this data availability and can thus be considered an improved successor of the Universal Product Code (in the remainder of this thesis simply referred to as barcode), with considerable opportunities for every part of the supply chain. This is mainly due to the fact that, in contrast to barcodes, multiple RFID tags can be read simultaneously by the same reader, and that a tag can carry and transmit a considerable amount of information (Delen et al., 2007). In terms of durability, an RFID tag also greatly surpasses the attributes of a barcode. Many tags are resistant to heat and are much less likely to be rendered unreadable by dirt or solvents and they can additionally be re-used, as one tag can be written over multiple times (Delen et al., 2007). Offering customized data storage directly linked to the product, RFID is a technology with great potential in a time where data analysis and the Internet of Things are gaining more and more attention.

\subsection{Review on RFID (SCM Literature)}

There is a considerable amount of literature on RFID in the supply chain management field. Many studies bring attention to the opportunities and advantages that RFID entails as a new technology in the retail industry, while others concentrate their research efforts on implementation hurdles and possible weaknesses of the technology itself. In the following, an overview of both sides will be given in an effort to provide an overview of the varying positions within supply chain management research. 


\subsubsection{Inhibitors}

A multitude of studies on possible implementation hurdles was conducted shortly after Walmart's announcement to establish RFID in its entire supply chain. This early research focused on potential issues such as data management and radio frequency (Angeles, 2004). Angeles (2004) explains that RFID entails major challenges in data management when implemented in the supply chain for two reasons. Firstly, storing and interpreting the extensive volume of data coming in at a very fast pace is a major challenge for most retail store operators. Secondly, every part of the supply chain needs to be integrated in the data processing system, because efficient tracking requires consistent data structures. This requires joint effort of every supplier and a high level of cooperation, which can be hard to achieve in very complex supply chain systems.

Another potential problem is the frequency that a tag uses to communicate with readers. There is no global standard for assigning frequencies for RFID purposes. Thus, a tag that operates on a certain frequency in one country might not be able to communicate with a reader on that frequency anymore once a border is crossed (Angeles, 2004). Additionally, other technological hurdles are highlighted, such as the content of the package that can negatively influence the readability of a tag (Clarke, Twede, Tazelaar, \& Boyer, 2006). As explained above, RFID tags use radio waves to communicate with a reader. Some materials, like liquids and metals, can interfere with those waves by absorbing or reflecting them, thereby negatively influencing the readability of the tag. According to Clarke et al. (2006), the positioning of the tag on the product and the orientation of the tag with regard to the reader also highly influence the readability.

Furthermore, RFID technology relies heavily on wide-spread adoption to add value for each user, comparable to the early days of telephony; when almost nobody else owns one, it does not make sense for an individual to purchase the technology. This is captured by Dew and Read (2007), who compare the network externalities of RFID to those faced by its antecedent, the barcode. They explain, that the barcode had almost failed to reach its universal acceptance, because retailers waited for manufacturers to start printing the barcodes on their products before investing in scanning equipment. At the same time, the manufacturers delayed printing barcodes on products until the retailers bought scanners. RFID tags experience a similar hurdle, considering that retailers who do not have a market power comparable to Walmart cannot impose the technology on their suppliers and thus only begin to invest in it once it is established among manufacturers. Those in turn cannot afford to be early adopters of a technology that will not be used by the retailers, making network externalities a critical point of the adoption process.

Finally, the costs including the initial investment, as well as maintenance and the price of the tags themselves are considered major drawbacks of the technology (Barut, Brown, Freund, May, \& Reinhart, 2006). As described above, the initial investment is considered too high by retailers and suppliers to overcome initial network externalities. In addition to those initial costs, Barut et al. considered continuous cost of buying tags one of the main drawbacks of implementing RFID in 2006. At the time, the price per transponder was between $\$ 0.25$ and $\$ 0.30$ (Barut et al., 2006). Over time these costs decreased to $\$ 0.07$ to $\$ 0.15$ for the more basic tags as a consequence of technological advancements (Dolgui \& Proth, 2012). According to Das and Harrop (2016), the price per tag will fall to $\$ 0.03$ in the next years. 


\subsubsection{Enablers}

Despite all the criticism, the positive aspects of RFID have been thoroughly investigated by many studies. The most obvious advantage is the possibility to track products throughout the entire supply chain and precisely manage inventory (Scott, 2005). According to Scott (2005), RFID technology connects both the physical flow of products and the flow of information throughout the entire supply chain, thereby creating great value for businesses.

More efficient material handling is considered another significant advantage, achieved by increasing the speed of logistics activities, while at the same time ensuring higher product quality and higher customer responsiveness (Azevedo \& Carvalho, 2012). Additionally, RFID helps to precisely determine the cost of each item sold (Barut et al., 2006). This is achieved by identifying the exact location, previous storage, transportation and other characteristics of a product; information provided by advanced RFID tags. Moreover, verifying the receipt of a product faster is a major advantage of the technology (Hardgrave \& Miller, 2006). Hardgrave and Miller (2006) consider this a way of improving existing processes by making them more effective and efficient using RFID.

Furthermore, out-of-stock items can be reduced (Riemenschneider, Hardgrave, \& Armstrong, 2007). This entails great potential for sales and customer satisfaction, as shown by Riemenschneider et al. (2007) who concludes, that the lower number of out-of-stock items achieved by using RFID tags in a case study translated into a one percent increase in sales. Although this number may not seem outstandingly high, it makes up multiple millions of U.S. dollars for big retailers like Walmart (Riemenschneider et al., 2007). The same study shows that unnecessary manual orders are avoided and product promotion is improved using RFID, thereby further strengthening the argument in favour of the technology.

Taking all the above-mentioned aspects into account, the question remains which of the factors de-motivating adoption are the most important concerns in practice and if those can be outweighed by the benefits of RFID. Further, a model based on the inhibitors and enablers explained above will be established as a basis for answering the research question.

\subsection{Review on Technology Adoption Models (IM Literature)}

The information management literature provides multiple models for technology adoption, which will be analysed with regard to their fit for RFID in the retail industry in the following section.

A very well-known model for technology adoption on an individual level is the technology acceptance model (TAM), which was first introduced by Davis (1986) to further the understanding of acceptance and implementation of a technology. His model identifies four key variables, perceived ease of use, perceived usefulness, and attitude towards the technology, which influence each other and the variable behavioural intention towards using. The attitude towards a technology thus determines whether or not it will actually be used, whereas the attitude itself is influenced by the perceived ease of use and perceived usefulness of the technology. While the TAM is applicable at an individual level, it cannot be easily transformed for use at the organisational level, which is a fundamental requirement for explaining the adoption of RFID in the retail industry. However, this model was further developed by Amoako-Gyampah and Salam (2004), who apply it specifically to enterprise resource planning (ERP), which is very closely linked to and somewhat enabled by RFID, for instance through improved inventory management. They propose that project communication and training on ERP systems influence the shared believe in the benefit of the ERP systems. While this model is much more applicable to the case $126 \mid$\begin{tabular}{l|l} 
Marble \\
Research \\
Papers
\end{tabular} 
at hand than TAM, it still fails to capture many important aspects that should be included when considering the adoption of RFID. Project communication and training alone will not increase the probability of implementing RFID in a supply chain, when fundamental problems lie with the technology itself, or when other major technological drawbacks occur as described in section 2.2.1. This model will therefore not be of much use to satisfyingly answer the research question.

Another technology adoption model is the unified theory of acceptance and use of technology (UTAU) (Venkatesh, Morris, Davis, \& Davis, 2003). It consists of the variables performance expectancy, effort expectancy, social influence, which influence behavioural intention, and facilitating conditions, which in turn predicts use behaviour together with behavioural intention. This model takes more diverse factors into account than the TAM, however it is still to a large extent focused on individual technology adoption. Additionally, it considers rather subjective factors, such as effort expectation, that might have a smaller impact on firm-level decision making than on an individual level. Moreover, this model shares a drawback with the TAM model in mainly considering the enablers of technology adoption, while paying less attention to possible inhibitors.

The successful adoption of information systems is also modelled by DeLone and McLean (1992). According to them, the quality of the system and the quality of the information that the system delivers impact both the use of and the user satisfaction with the information system. Those in turn influence the individual performance, which then shows the impact on organisational performance. Again, the underlying problem of this model is its focus on the individual performance, which is only translated into organisational performance at a very late stage of the process. To find out what enables and inhibits the adoption of RFID in the retail industry, a model is needed which generally takes on a firm-level perspective.

Summarizing, each of the above described models have shortcomings that greatly restrict their explanatory value for the question at hand. Less attention is paid to the application from an organisational point of view. Furthermore, all of these models focus primarily on the positive factors that enable the use of the technology while paying much less attention to the inhibitors that might prevent the technology's success. This critical curtailment was recognized by Cenfetelli (2004), who introduced a two-factor model including both inhibitors and enablers of technology adoption. This two-factor approach has been used in multiple information management related studies before. $\mathrm{Ng}$, Matanjun, D'Souza, and Alfred (2015) apply it to explain inhibitors and enablers of the adoption of a mobile medical app in pharmaceutical practice. They find empirical support for six positive and two negative factors, showing that although the two-factor approach takes both inhibitors and enablers into account, models do not necessarily need to be evenly balanced between positive and negative determinants, an insight that allows for more flexibility when establishing and adjusting a two-factor model. A study by Moilanen, Salo, and Frank (2014), focused on the use of an exercise tracking system, also uses the two-factor approach. They specify that for technology, a perceived inhibitor might be a neutral characteristic that inhibits the adoption of a technology because there are no clear instructions or the design is not thought through. This is an important point to consider when establishing a new two-factor model and evaluating its outcome, because the perceived negativity of an attribute might not be caused by the attribute itself, but by its implementation. 


\section{Model}

As shown above, there are many possible inhibitors and enablers concerning RFID technology, and many models that attempt to capture variables of technology adoption. Following the reasoning explained above, the two-factors approach is a suitable model and therefore used for the case at hand.

Building on the findings of previous research in the supply chain management area, the following inhibitors were identified: complexity, frequency, integration, network effect, readability, and costs. 'Complexity' refers to the complexity of the data generated by the RFID technology, as well as the complex challenge of analysing and interpreting that data in a meaningful way. The inhibitor 'frequency' measures technological problems related to the radio waves sent by the tags, such as varying national regulations on frequency use. 'Integration' abbreviates the integration of the technology in the company, reflecting the support that both executives and employees show towards the use of RFID. Closely related, but more outward-focused, is the inhibitor 'network effect'. It indicates the problems arising from network externalities that the technology faces when the adoption rates are too low to add sufficient value for a single user. 'Readability' reflects problems with the communication between the tag and the reader, which might be impaired by certain materials and the positioning of the tag. As described before, 'Costs' have been identified as a potential inhibitor by previous studies, in this model the term incorporates both the initial investment in equipment, as well as maintenance costs that occur over time.

The literature review regarding the benefits of RFID reveals six potential enablers: automated orders, reduce out-of-stock, traceability, material handling, cost determination, and receipt verification. The enabler 'automated orders' implies the benefit of excluding manual orders and thereby solely ordering items that are truly needed, without the possibility of human misjudgement. Similarly, 'reduce out-of-stock' reflects the ability to precisely measure inventory and have complete information on all items in inventory. Through this increased transparency, the number of out-of-stock items can be reduced. Another enabler is 'traceability', referring to the ability to know exactly where different items are located in the supply chain, as well as retrieving a variety of information on one specific item. The potentially most convincing argument in favour of RFID concerning efficiency is the enabler 'material handling'. It describes the ability of many RFID tags to be read at the same time by one reader, as well as the ability of the reader to read tags that are relatively far away. As shown by the inhibitor 'readability' this might not always work perfectly, but it nevertheless remains one of the main selling points of the technology. The enabler 'Cost determination' is closely linked to 'traceability', although it focuses on a different aspect. Here, the aim is to determine exactly how much money was invested in the final product, including every potential cost, such as transportation and storage, that would otherwise be very difficult to determine for a single item. Identifying the exact cost structure of certain items can be very helpful in improving the supply chain as a whole. Finally, 'receipt verification' shows the value of the increased speed of delivery of information and the value derived from high connectivity between suppliers, manufacturers, distributors and retailers. A retailer that uses RFID technology to register received items is able to immediately adjust inventory, again leading to much higher levels of precision. While the above stated inhibitors discourage the adoption of RFID, the enablers reflect the opposing direction, pushing forward the adoption in the retail industry. Figure 1 shows the proposed model which will be tested by the expert interviews as presented hereafter. 
Inhibitors

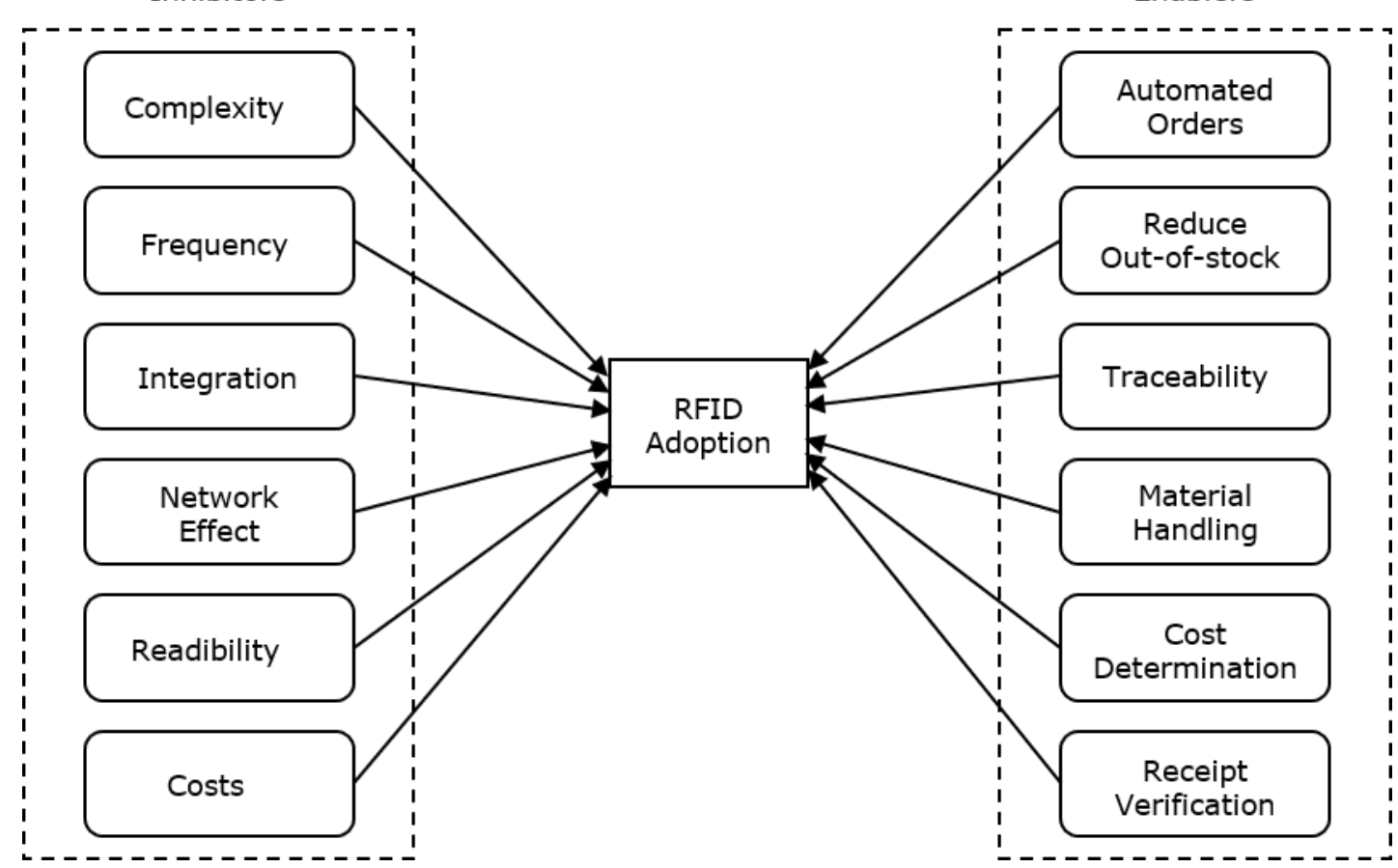

Figure 1. Two-factor RFID adoption model.

\section{Methodology}

\subsection{Method}

To test the two-factor RFID adoption model, interviews were conducted with three experts in the field. Interviews are the most suitable testing method in this case because they allow deep insights into the issue of RFID adoption from different angles. Additionally, by choosing suitable respondents, a high level of expertise is guaranteed, which increases the credibility and reliability of the tested model. Other potential sources of data were found less meaningful.

A database would for instance provide objective data on the number of firms adopting RFID, yet it would only allow for a very limited insight into the reasons for adoption or, perhaps even more importantly, the reasons for not adopting RFID technology. Therefore, a statistical analysis based on a database is regarded suboptimal for testing the model at hand.

A method that allows more specific insight into benefits and problems of the technology is conducting a survey by sending questionnaires to experts on RFID. However, this method contains some severe limitations. Not only would it be very difficult to find a sufficiently high number of suitable respondents, it would also be challenging or even impossible to avoid biases such as nonresponse or voluntary response bias (Sharpe, De Veaux, \& Velleman, 2012). Those biases are avoided by conducting interviews with a more limited number of experts. All of the respondents that were asked to participate agreed to do so and the selection of experts ensured that not only extreme opinions were represented, thereby avoiding the main negative consequence of voluntary response surveys. Considering the advantages of interviews and the shortcomings of possible alternatives, expert interviews are the most favourable choice to test the presented model. 


\subsection{Respondents}

The three respondents were chosen for the interviews because of their strong involvement in RFID. While they have all worked with RFID in the retail industry, their different backgrounds contribute to the diversity of information to be retrieved in the interviews. Respondent A is a German college professor who focuses his research on the selection and introduction of business information systems, as well as IT for optimizing logistics processes. This certainly qualifies him as a suitable expert in the academic field. The two other respondents obtained their knowledge on RFID from working in the industry. Respondent $B$ is the co-founder and managing partner of a Swiss consultancy specialized in providing IT solutions to retail companies. Respondent $\mathrm{C}$ managed the RFID project of a market leader in the fastmoving consumer goods industry. Therefore, three very different fields are represented: academic research, consulting, and business.

\subsection{Interview Structure}

The respondents were given a list of questions (see appendix) in advance, which served as a basis for the structure of the interview. The interviews were conducted on the phone. The interview questions were structured in two distinct parts, the first focused on the implementation hurdles of RFID in the retail industry while the second part put emphasis on the benefits of the technology. In each part, the respondents were first asked to simply rank the importance of certain positive and negative aspects with regard to the implementation of RFID. Then, the respondents were asked to elaborate on high- and lowranked items. Further, detailed questions were asked based on interesting aspects identified in the literature review. In the end, the respondents were given the opportunity to make additional comments or remarks.

\section{Results}

The three respondents' opinions differed widely in many aspects. The simple rating of inhibitors and enablers of RFID, shown in Table 1 and 2, gives a first indication of the different standpoints of the respondents. The respondents rated the items on a scale from very unimportant (1) to very important (5). Generally, the opinions of respondent A and B are more closely aligned to each other than to the one of respondent $\mathrm{C}$.

In the following sections, an overview of the respondents' view on the inhibitors and enablers will be given, followed by an extensive explanation of the respective responses.

\section{$5.1 \quad$ Inhibitors}

Six inhibitors were discussed during the interviews, two of which were rated important or very important by the respondents. The only item which was considered very important by all three respondents is the negative network effect. In descending order and according to total rating, the negative network effect is followed by high costs, poor integration in the company, and complex data management. The most disputable hurdles are frequency issues and technological issues (to be interpreted as issues regarding the readability of the tags etc.), both were rated very important by respondent $B$ and very unimportant by respondent $\mathrm{C}$. Respondent $\mathrm{A}$ had a neutral opinion on both. In addition to the six proposed ones, three new inhibitors were identified. Respondent $A$ introduced error rate and data privacy as a hurdle of 
importance, whereas respondent C considered the perception of the technology a very important inhibitor.

\begin{tabular}{|l|c|c|c|}
\hline & \multicolumn{3}{|c|}{ Respondent } \\
\hline Inhibitors & A & B & C \\
\hline $\begin{array}{l}\text { Complex data management } \\
\text { Frequency issues }\end{array}$ & 4 & 4 & 2 \\
\hline $\begin{array}{l}\text { Poor integration in the } \\
\text { company }\end{array}$ & 3 & 5 & 1 \\
\hline $\begin{array}{l}\text { Negative network effects } \\
\text { Technological issues }\end{array}$ & 5 & 5 & 5 \\
\hline $\begin{array}{l}\text { High costs (initial + } \\
\text { maintenance) }\end{array}$ & 3 & 5 & 1 \\
\hline $\begin{array}{l}\text { Others } \\
\text { Error rate }\end{array}$ & 4 & 5 & 4 \\
\hline $\begin{array}{l}\text { Data privacy } \\
\text { Perception of technology }\end{array}$ & - & - & 5 \\
\hline
\end{tabular}

Table 1. Inhibitors.

\begin{tabular}{|c|c|c|c|}
\hline \multirow[b]{2}{*}{ Enablers } & \multicolumn{3}{|c|}{ Respondent } \\
\hline & $\boldsymbol{A}$ & $\boldsymbol{B}$ & C \\
\hline $\begin{array}{l}\text { Decrease unnecessary } \\
\text { manual orders }\end{array}$ & 4 & 3 & 1 \\
\hline Reduce out-of-stock items & 5 & 3 & 3 \\
\hline $\begin{array}{l}\text { Traceability through the } \\
\text { supply chain }\end{array}$ & 4 & 5 & 5 \\
\hline $\begin{array}{l}\text { More efficient material } \\
\text { handling }\end{array}$ & 5 & 5 & 3 \\
\hline $\begin{array}{l}\text { Exact cost determination of } \\
\text { sold items }\end{array}$ & 1 & 2 & 1 \\
\hline $\begin{array}{l}\text { Faster product receipt } \\
\text { verification }\end{array}$ & 4 & 5 & 2 \\
\hline \multicolumn{4}{|l|}{ Others } \\
\hline Internet of Things & 3 & - & - \\
\hline On-shelf availability & - & - & 4 \\
\hline Promotion tracking & - & - & 5 \\
\hline
\end{tabular}

Table 2. Enablers.

As the most highly ranked inhibitor, negative network effect was explained to be a major drawback because a high level of coordination among all supply chain partners is required to overcome this problem. This high level of coordination is very difficult or impossible to reach in complex supply chain systems and is therefore striking drawback. Another, closely linked explanation for the severity of this problem is the limited power that both suppliers and retailers face when trying to implement the technology. Respondent B stated that, because the tags have to be attached to the product in the very beginning of the supply chain, from a retail perspective it is very hard to force all suppliers and their respective second-tier suppliers to implement the technology. Respondent $\mathrm{C}$, representing the supplier side, described that even as a market leader, one supplier alone only accounts for a very low percentage of a retailer's sales. Therefore, the retailer would not be willing to invest in the technology if only one supplier expresses the wish to do so. This shows that every party involved on both the supplier and the retailer side needs to be determined to implement RFID, otherwise adopting the technology is impossible.

The costs of the technology, defined as the initial investment and the subsequent maintenance costs of equipment, was considered important by all respondents. However, they put attention on a much more pressing cost issue; the RFID tags themselves. As described before, the least expensive RFID tags cost around $\$ 0.07$ per piece today. This is considered a minor cost in some retail industries such as clothing retail, where profit margins are relatively high. In other sectors like retail of food and beverages, the profit margins may be lower than the value of the tag. Then, placing a tag on each food item, for instance in a supermarket, would not be financially feasible. Giving a more positive outlook, respondent $A$ explained that the costs will most likely further decrease in the future, when the production processes progress. It can also lead to decreased labour costs, because the scanning and checkout can be completed without assisting staff members. Nonetheless, to this day the high costs of 
the individual tags are still a major drawback of the technology and one of the main reasons for its slow adoption.

Another aspect that was considered relatively important by the respondents is poor integration in the company in the sense of little support shown by executives and employees. Although they clarified that this is the case for nearly all new technologies and not an aspect unique to the adoption of RFID, it remains a drawback for the adoption of the technology. Similar opinions were voiced on the issue of complex data management, with all respondents stating that while this might pose a great challenge on the involved companies, it is a frequently faced problem in an increasingly data-driven society. Therefore, this aspect is again not an issue exclusively experienced during the adoption of RFID. Respondent $C$ rated this item as unimportant for this very reason, claiming that firms need to handle more and more data regardless of whether or not they implement this specific technology.

Opposing points of view were expressed by respondents $B$ and $C$ regarding frequency issues and technological issues, while respondent $A$ was neutral towards both. The high rating by respondent $B$ as opposed to the low one given by respondent $\mathrm{C}$ can be explained by taking their different backgrounds into account. Respondent B works as a consultant with many different customers in the retail industry, who all face different problems. In his experience, frequency issues are a major drawback of the technology because they severely impair its added value of the technology to his clients' products. Additionally, he did not believe that there is a solution for the frequency problem. At the same time, respondent $\mathrm{C}$ works for a company with a relatively limited product scope. She did not consider the higher or lower frequencies a problem for her project and also did not incur problems with different national frequency regulations. She explicitly stated that different problems might arise for other products and that frequency issues become more pressing as supply chains become more globalized. However, because she has not yet faced any frequency issues herself, she rated them less important than respondent $\mathrm{B}$ did.

Upon more detailed questioning on the topic of scanning accuracy of packages containing metal or liquid, the respondents provided very different opinions. Respondent A stated that the problem in general is not surmountable, underlining the severity of the problem. He also drew attention to possible solutions for certain products such as replacing metal shopping carts with plastic equivalents. Additionally, he specified that not all products are affected, the clothing retail industry suffers much less from this problem than the beverage retail industry for instance. Respondent B claimed that the readability problem can be somewhat overcome using tag spacers that place the tags in certain positions and thereby allow metallic products to be identified by the reader. He also again pointed to the problems with the frequency of the waves used by the tags. According to him, the range of the tag is very unreliable and can in some cases lead to an incomplete, holey picture of the batch being scanned. Respondent $\mathrm{C}$ put attention to the complex details that have to be considered when discussing the readability of metal and liquid, small things such as metallic wraps around chocolate bars can severely impair the readability of the tag. She pronounced a different solution to this problem, an algorithm that uses big data to predict the perfect location of a tag when it is provided with detailed information about the product to be scanned. This increases the readability of the tags by far and provides an alternative to the commonly used trial-and-error method for finding the best spots for the tags.

These different approaches to a solution are reflected in the rating, when a satisfying solution is discovered, the inhibitor is of course accredited much less importance. Respondent B introduced tag spacers for the placement of tags on metallic products, which is an improvement, but by no means a 
perfect solution. The algorithm explained by respondent $C$ is per contra applicable to a variety of materials, it overcomes the issue of tag placement in a much more versatile manner than tag spacers.

Other, related technological issues are again rated much lower by respondent $C$ than respondent B. According to respondent $C$, the set-up of a new technology is always difficult, especially the matching of new technologies with older legacy systems. Nonetheless, this is again not a unique RFID-related problem and should therefore not be considered a major hurdle.

In addition to the six inhibitors that were tested during the interview, additional inhibitors were introduced. The first one, the error rate, was pointed out by respondent A. It is closely connected to the technological and frequency issues described above. The respondent drew attention to this point to show that, even with possible solutions such as tag spacers and tag-placing algorithms, the error rate in reading many products at the same time is too high for many applications. This is supported by the other respondents, who also consider one hundred percent reading accuracy rather utopic. Respondent A rated this inhibitor as important, which is confirmed by respondent $B$, who voiced a similar opinion. Respondent $\mathrm{C}$ considered this problem less severe because full accuracy is not required in the settings that she operates in.

Another inhibitor brought up by respondent $A$ is data privacy. He explained that tags could theoretically be continuously tracked, even after the product has moved to the customer's ownership, thereby effectively spying on the customer. Although the tags can be disabled upon check out, he considered this a major issue, because so far insufficient regulation is in place and disabling the tags is mainly the responsibility of the retailers. Therefore, data privacy concerns arise that may greatly impair the success of the technology.

An entirely different additional point is made by respondent $C$, who showed that the perception of RFID is a major drawback in all efforts to convince supply chain partners of its superiority. She showed that the technology is perceived as old and outdated, and therefore seems rather unattractive at first glance. According to her, this perception can somewhat be shifted into a more positive direction by bringing attention to the use of the technology in modern everyday products, such as smartphones and car keys. Nonetheless, the poor reputation of the technology has a severely negative effect on adoption, and the initial hype is long gone.

\subsection{Enablers}

When discussing the benefits of RFID technology, there was no consensus among the respondents about the most important aspect. The highest rated enabler was traceability of the product throughout the supply chain, closely followed by more efficient material handling. Reducing out of stock is the next highest rated benefit, together with faster product receipt verification. The latter appears to be a controversial topic, rated unimportant by respondent $\mathrm{C}$ and very important and important by respondents $B$ and A respectively. Reducing unnecessary orders was also rated differently by all three respondents, however the differences were less severe in this case. Consistently ranked as unimportant and very unimportant is the exact cost determination of sold items. Additionally, three new enablers were discussed. Respondent A proposed the Internet of Things and the therein included opportunities for the use of RFID technology in a more connected world. In this context, the Internet of Things is defined as an infrastructure that provides a network connecting information technologies and everyday items 
(Atzori, Iera, \& Morabito, 2017). Respondent C mentioned the determination of on-shelf availability and the possibility of promotion tracking as two important additional enablers.

The highest rated enabler of RFID in the retail industry is the traceability of the product throughout the supply chain. There are multiple explanations for its importance, improved quality and time management are two major advantages named by respondent $B$. Respondent $A$ emphasised the importance of RFID in reverse logistics, for instance in overcoming a product harm crisis. During a recall, precise information on the location of each product is highly valuable. It enables faster identification of required processes and allows for a more effective recall process.

More efficient material handling also emerged as an enabler of high importance. Respondent $\mathrm{A}$ pointed towards the versatility of this benefit, showing that it can be used to improve processes both concerning the product receipt at the retailer and the scanning at the cashier. Generally, scanning many different products at the same time is a major advantage of RFID over the barcode. It is further strengthened by the option of retrieving detailed information about all the scanned products in an instant. Still, respondent $C$ showed a neutral opinion on the importance of material handling. On the one hand, she regards the technology to be of great value in some parts of the retail industry, such as in ecommerce retail, where many different products are on one palette. On the other hand, this advantage becomes negligibly small when considering a retailer that receives products in batches. When a palette contains only one product, cheaper scanning technologies provide sufficient accuracy. It is not necessary to scan every single piece on a palette when it contains a predetermined amount of the same product. Then, a barcode is a cheaper and perhaps even more precise option.

Another enabler, product receipt verification, is assigned very different levels of importance due to multiple factors. First of all, RFID increases the speed and efficiency of the product receipt processes at the retailer. The argument made by respondent $B$ is that it allows for verifying bulks of products which are then instantly and automatically added to the inventory, allowing more efficient inventory management. A similar argument is brought forward by respondent A. Respondent C per contra states that the importance of this advantage will decrease in the future, when other technologies mature and instant inventory taking will no longer depend on RFID technology. Again, most potential lies in the instant verification of different products at the same time, which is a great advantage of RFID over the barcode and similar technologies.

Reducing out-of-stock items was not consistently rated as important, two of the respondents labelled it neutral. Interestingly, in contrast to previous cases, here the two respondents from the industry rated the enabler equally, whereas respondent A from the academic field displayed a different opinion. Only respondent $A$ assigned high importance to the reduction of out-of-stock items. This may be the case because the problem of high levels of out-of-stock items is overrepresented in the academic literature, but not a very pressing issue in the retail business. Respondent B explained that there are other, sufficient tools for inventory management, such as real-time inventory trackers at the cashier. However, he explained that cashiers do not always use the systems accurately enough. Different types of very similar products may be misregistered as multiple items of the same product, which decreases the accuracy of the present systems. He further acknowledged that RFID enables the retailer to drastically decrease the process of physical inventory taking, thereby potentially cutting costs. Respondent $C$ further explained the limited importance of RFID in reducing out-of-stock items in the retail industry. She argued that while it is indeed a problem for many retailers that stolen products are not registered in standard check out systems and inventory is thus overstated, the systems currently in 
place are precise enough and much cheaper than RFID. This explanation reoccurs throughout the argumentation of all three respondents. It seems that in many cases the legacy systems are much less accurate than RFID, but still considered sufficiently precise by the industry and have a major cost advantage over RFID.

The other item falling into the category of more precise inventory management, decreasing unnecessary manual orders, which received similar ratings. Respondent A and B rated it neutrally whereas respondent $C$ regarded it as unimportant. She argued that the systems currently in place are already highly automated and that the risk of unnecessary manual orders having a large negative impact is therefore very low. Respondent A and B lean to a slightly more positive perception, because RFID technology could still further decrease the likelihood of unnecessary manual orders.

The most clearly unimportant enabler is cost determination. Respondent B stated that this is a rather unimportant aspect that would not contribute to convincing reluctant supply chain partners to adopt the technology. Respondent $C$ shed light on the retailer's perspective; when the retailer does not own warehouses and uses third party logistics providers for transporting the products to the retail outlet, there is no need for detailed cost determination of a product. The cost of each product for the retailer is already easily determinable and does not require additional transparency.

The first additional enabler, promising high future benefits of RFID, is its contribution to the Internet of Things. Respondent A proposed that in the future, intelligent shopping carts or changing rooms could utilize the information stored on RFID tags. For instance, an intelligent changing room could connect the selected pieces and show potential accessorizing options. This would only be possible with an RFID tag on every single product and therefore presents an immense opportunity.

On the problem-solving side, another enabler of RFID was presented by respondent C. RFID technology could help overcome the so-called NOSBOS (not on shelf but on stock) problem that occurs, when a retailer is unable to identify which items are unavailable to the customer even though they are in stock. This is another facet of the out-of-stock problem described before, but the NOSBOS problem is much harder to overcome using traditional systems. RFID technology allows the retail store personnel to know exactly where items are located at any point in time.

Another enabler of RFID in the retail industry, particularly for the suppliers of the retailer, is promotion tracking as shown by respondent $C$. When a product is set up for promotion, the firm supplying the product to the retail outlet cannot be certain that the product will actually reach the promotion stand instead of simply being displayed on a regular shelf. RFID tags would allow detailed monitoring. Additionally, RFID technology would enable market researchers to determine if promotions are effective, by detecting which products were bought off the regular shelves and which were picked at promotion stands. This is highly valuable information that is not accessible without RFID technology. 


\subsection{Inhibitors and Enablers Compared}

In the end of the interviews, the respondents were asked whether the enablers outweigh the inhibitors of RFID in the retail industry in their opinion. All respondents answered this final question in the same manner. They considered RFID promising and beneficial for the clothing retail sector but not for other parts of the industry, such as grocery retail. The benefits for the clothing retail are very high, whereas for the grocery retail the inhibitors are too severe to be outweighed by the enablers.

Summarizing, the respondents revealed the flaws and strengths of the model proposed in section 3. The expert interviews made clear that adjustments need to be made to improve the meaningfulness of the model and its explanatory power with regard to the initial research question. Therefore, the initial model was revised.

\section{Revised Model and discussion}

The results of the expert interviews confirm some parts of the above proposed model, reject others and add several new enablers and inhibitors. Based on the results provided above, a revised model is established. Figure 2 shows the changes made in the model.

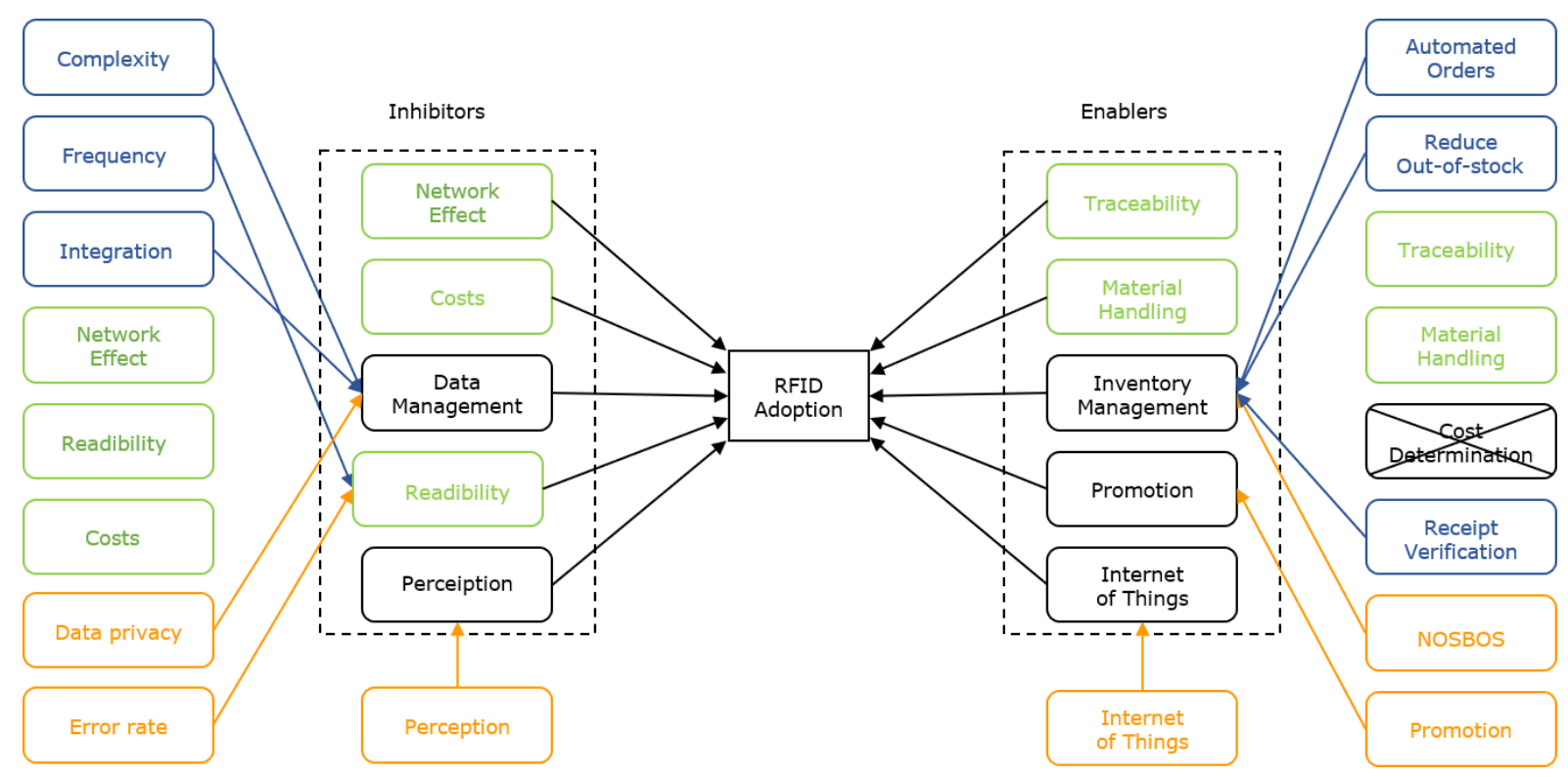

Figure 2. Revision of the two-factor RFID adoption model.

The centre of the above presented model shows the revised model, the areas on the far left and right show previous and newly added inhibitors and enablers to visualize the revision. Inhibitors and enablers taken over with minor or no changes from the previously proposed model are marked green on the sides, as well as in the revised model, to facilitate the interpretation of the figure. Previous inhibitors and enablers that were re-grouped for the revised model are marked blue, the corresponding arrows indicate the adjustments. The discarded enabler is crossed out. The newly added factors are shown in orange, the arrows illustrate their position in the revised model. In contrast to the original model, the order of inhibitors and enablers in the revised model reflects the importance of the respective factors. The relative importance of each inhibitor and enabler is derived from the arguments brought forward in the

\section{Research Papers}


interviews as discussed in the previous section. The following section explains the changes in further detail.

The revised model includes three of the previous inhibitors and introduces two new ones. The first retained inhibitor is the 'network effect'. The negative network effect associated with the adoption of RFID technology has been rated as very important by all three questioned experts. It is therefore the most important inhibitor of the technology. Also, consistently rated as important are 'costs'. Therefore, this inhibitor remains in the revised model. However, the new model does not only bring attention to the costs associated with the initial investment and maintenance of the equipment, but focuses on the continuously arising costs of purchasing tags for the products. The previous inhibitor 'readability' has also been transferred into the revised model. However, it now not only incorporates readability issues regarding the scanning of products containing metal or liquid, but also includes the generally high error rate and the frequency issues described above. These two inhibitors were rated controversially, but taken together with the issues related to scanning different materials, the new inhibitor 'readability' takes all respondents' arguments into account. The new inhibitor 'data management' combines the previous inhibitors data complexity and integration in the company. Furthermore, it covers the newly introduced inhibitor 'data privacy', thereby again taking into account the different points that the respondents focused on. Lastly, the new inhibitor 'perception' is introduced. It emphasises that the negative perception of RFID can severely impair adoption efforts as explained by respondent C.

On the enabler side, two of the old factors are retained while three new ones are introduced. The most highly rated items, 'traceability' and 'material handling', are taken over from the previous model without any interpretational changes due to the consistency in the respondents' ratings. More efficient 'inventory management' is additionally introduced, covering the benefits of faster product receipt verification, automated orders, reduced out-of-stock and decreased NOSBOS likelihood. Standing alone, the impact of these factors was not generally considered important by all respondents, with the exception of product receipt verification, which was rated as important by two of the three respondents. Taking into account all arguments put forward by the respondents and the fact that each of the incorporated items was regarded as important by at least one respondent, the more general enabler 'inventory management' certainly adds explanatory value to the model. With 'promotion', another new enabler is added. It explains the above described advantages of RFID for promotion tracking shown by respondent C. Additionally, the factor 'Internet of Things' is taken into account by the revised model. As described above, this enabler will likely become a great advantage in the future for both the grocery retail and the clothing retail industry.

Summarizing, the revised model reflects the results of the interviews and therefore represents the real situation of RFID in the retail industry much more accurately than the previous one. It covers different, more important aspects and makes sure that different perspectives are included. The revised model therefore serves as a basis to answer the research question in the following section, it is presented in its final version in Figure 3. 


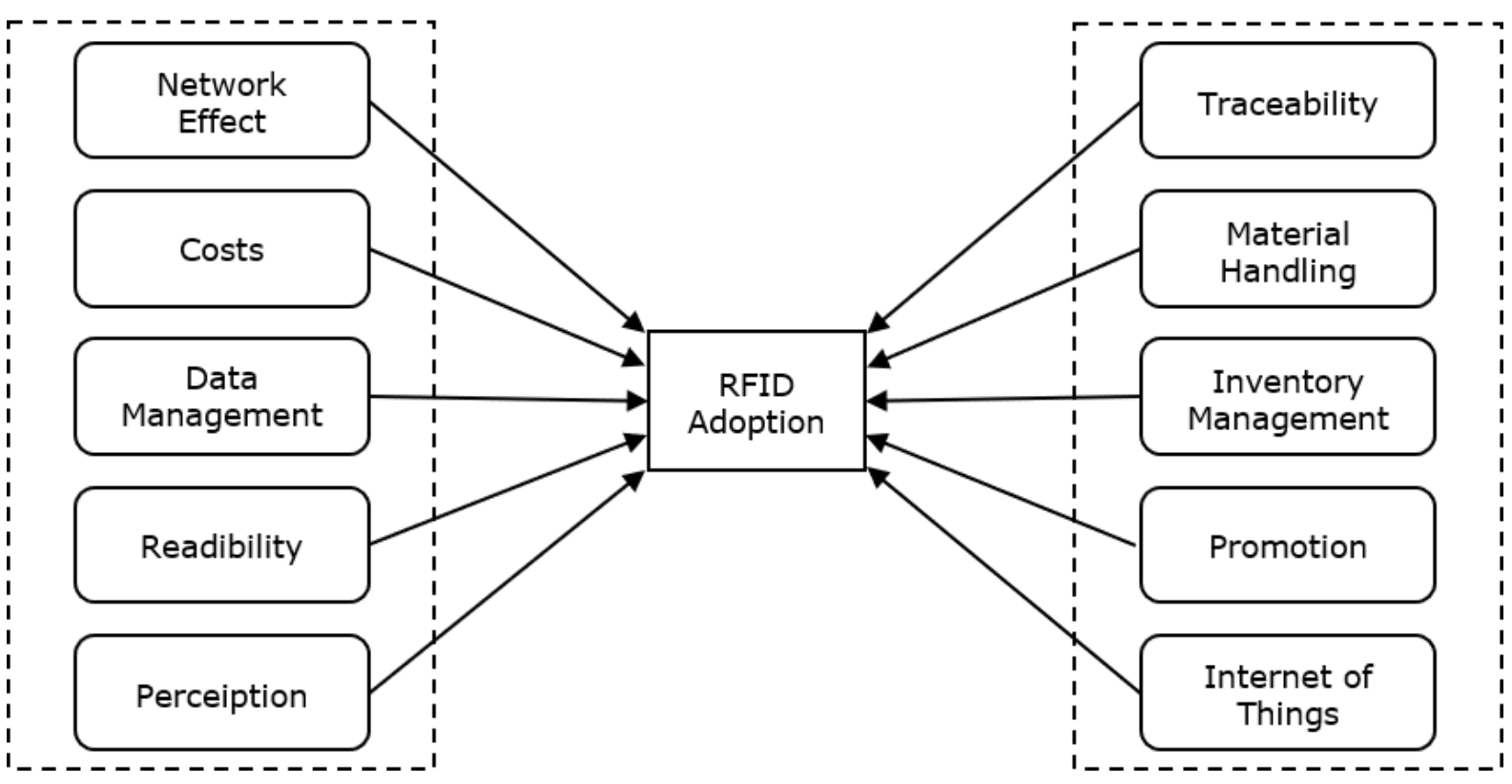

Figure 3. Revised two-factor RFID adoption model.

\section{Implications and Limitations}

The two-factor RFID adoption model serves as a guide for identifying problems and benefits that may arise when implementing the technology in the retail industry. It can be used as an explanatory approach when analysing the state of RFID adoption in a distinct sector of the industry, or of the retail industry as a whole. By highlighting inhibitors, the model can serve as a basis for future improvements of the technology, reflecting what the users at different points of the supply chain are interested in. It also points out potential future enablers that will positively influence the adoption of the technology at a later point in time. Summarizing, the model offers a variety of potential use cases applicable to both academic and business settings.

Nevertheless, the model is not flawless. It takes into account a broad range of literature and the knowledge of three experts, but some inhibitors and enablers may have been overlooked in the analysis. Additionally, the focus is on the Western European market, leaving unclear whether or not the outcomes are generalizable on a broader international level. Finally, the focus lies on the industry as a whole and, more specifically, on the clothing and grocery retail. Very specific niche retail sectors may face entirely different enablers and inhibitors that this model fails to capture. Specific sectors and a broader range of countries could be the focal point of future research, along with methods going beyond literature review and expert interviews to confirm the reliability and meaningfulness of the model.

\section{Conclusion}

The revised two-factor adoption model presented above serves one main purpose; answering the initial research question: 'What are the implementation issues of RFID in the retail industry?'. The model shows both enablers and inhibitors for the adoption of RFID technology. The most important inhibitors that were identified in the supply chain management literature and confirmed by the expert interviews 
are the negative network effect and the high per-tag costs of RFID. Additionally, data management, readability, and perception were defined as inhibitors and therefore symbolize negative implementation issues. The main enablers of RFID in the retail industry were found to be traceability and material handling. Moreover, inventory management, promotion tracking, and the Internet of Things represent additional enablers and thus positive implementation issues. While those enablers and inhibitors reflect the current situation in the retail industry as a whole, they are weighed differently in separate subsectors of the industry. In the interviews, the main distinction was made between clothing retail and grocery retail. Currently, the enablers are more significant than the inhibitors in the clothing retail, whereas the opposite is true for grocery retail. There, the negative network is a major issue, because the power of the retailers is too low to force the implementation of RFID onto suppliers, while the supplier power is too low to have an impact on the retailer. Additionally, the grocery industry faces very low profit margins per product, which may sometimes be exceeded by the costs of an RFID tag, leading to a negative contribution margin. In contrast, the clothing retail industry highly benefits from the technology because the relatively high profit margins allow for the investment in RFID tags, which can then be used to track the items in a just-in-time supply chain. Moreover, the clothing industry often has very diverse products shipped on the same load, thereby increasing the benefits retrieved from scanning many items at the same time.

Considering all this, it is not surprising that the clothing industry is in the course of establishing RFID as a retail standard, with more than seventy percent of U.S. apparel retailers conducting pilots or moving beyond those towards broader adoption, whereas the technology is so far only used in very few grocery retail stores (Hardgrave \& Patton, 2016). This shows, that the model above needs to be interpreted taking the characteristics of the focal industry into account. While it generalizes the most important aspects for all retail industries, each specific one may place different weight on the inhibitors and enablers.

\section{References}

Amoako-Gyampah, K., \& Salam, A. F. (2004). An extension of the technology acceptance model in an ERP implementation environment. Information \& Management, 41(6), 731-745. doi:http://dx.doi.org/10.1016/j.im.2003.08.010

Angeles, R. (2004). Rfid Technologies: Supply-Chain Applications and Implementation Issues. Information Systems Management, 22(1), 51-65.

Atzori, L., Iera, A., \& Morabito, G. (2017). Understanding the Internet of Things: definition, potentials, and societal role of a fast evolving paradigm. Ad Hoc Networks, 56, 122-140. doi:http://dx.doi.org/10.1016/j.adhoc.2016.12.004

Azevedo, S. G., \& Carvalho, H. (2012). Contribution of RFID technology to better management of fashion supply chains. International Journal of Retail \& Distribution Management, 40(2), 128-156.

Barut, M., Brown, R., Freund, N., May, J., \& Reinhart, E. (2006). RFID and Corporate Responsibility: Hidden Costs in RFID Implementation. Business and Society Review, 111(3), 287-303. doi: $10.1111 / \mathrm{j} .1467-8594.2006 .00273 . x$

Cenfetelli, R. T. (2004). Inhibitors and Enablers as Dual Factor Concepts in Technology Usage. Journal of the Association for Information Systems, 5(11/12).

Clarke, R. H., Twede, D., Tazelaar, J. R., \& Boyer, K. K. (2006). Radio frequency identification (RFID) performance: the effect of tag orientation and package contents. Packaging Technology and Science, 19(1), 45-54. doi:10.1002/pts.714

Das, R., \& Harrop, P. (2016). RFID forecasts, players and opportunities 2016-2026. IDTechEx Report.

Davis, F. D. (1986). A technology acceptance model for empirically testing new end-user information systems: Theory and results. Massachusetts Institute of Technology.

Delen, D., Hardgrave, B. C., \& Sharda, R. (2007). RFID for Better Supply-Chain Management through Enhanced Information Visibility. Production \& Operations Management, 16(5), 613-624. 
DeLone, W. H., \& McLean, E. R. (1992). Information Systems Success: The Quest for the Dependent Variable. Information Systems Research, 3(1), 60-95.

Dew, N., \& Read, S. (2007). The more we get together: Coordinating network externality product introduction in the RFID industry. Technovation, 27(10), 569-581. doi:http://dx.doi.org/10.1016/j.technovation.2006.12.005

Dolgui, A., \& Proth, J.-M. (2012). Radio Frequency IDentification (RFID) in Supply Chain: Technology and Concerns. IFAC Proceedings Volumes, 45(6), 49-56. doi:http://dx.doi.org/10.3182/20120523-3-RO-2023.00448

Hardgrave, B. C., Langford, S., Waller, M., \& Miller, R. (2008). MEASURING THE IMPACT OF RFID ON OUT OF STOCKS AT WAL-MART. MIS Quarterly Executive, 7(4), 181-192.

Hardgrave, B. C., \& Miller, R. (2006). The myths and realities of RFID. International Journal of Global Logistics \& Supply Chain Management, 1(1), 1-16.

Hardgrave, B. C., \& Patton, J. (2016). 2016 State of RFID Adoption Among U.S. Apparel Retailers. Auborn University RFID Lab, 6.

Joshi, Y. V. (2000). Information visibility and its effect on supply chain dynamics. Massachusetts Institute of Technology. Department of Mechanical, Engineering. Retrieved from http://hdl.handle.net/1721.1/9052 WorldCat.org database.

Moilanen, P., Salo, M., \& Frank, L. (2014). Inhibitors, enablers and social side winds Explaining the use of exercise tracking systems. Proceedings of the 27th Bled eConference" eEcosystems"(pp. 2337). Edited by In A. Pucihar, C. Carlsson, R. Bons, R. Clarke, \& M. Borstnar. Kranj: Moderna organizacija. ISBN 978-961-232-276-2.

Ng, S.-N., Matanjun, D., D'Souza, U., \& Alfred, R. (2015). Understanding Pharmacists' Intention to Use Medical Apps. electronic Journal of Health Informatics; Vol 9, No 1 (2015): Special Issue on Informatics for Ageing and Aged-Care; e7.

Riemenschneider, C., Hardgrave, B., \& Armstrong, D. (2007). Is there a business case for RFID? AMCIS 2007 Proceedings, 325.

Scott, S. (2005). Enabling supply-chain strategies with RFID. Logistics \& Transport Focus, 7(7), 41-44.

Sharpe, N. R., De Veaux, R. D., \& Velleman, P. F. (2012). Business Statistics (second ed., pp. 29-39): Pearson.

Ton, Z., Dessain, V., \& Stachowiak-Joulain, M. (2009). RFID at the Metro Group: Harvard Business School.

Venkatesh, V., Morris, M. G., Davis, G. B., \& Davis, F. D. (2003). USER ACCEPTANCE OF INFORMATION TECHNOLOGY: TOWARD A UNIFIED VIEW. MIS Quarterly, 27(3), 425-478. 


\section{Appendix Interview Questions}

1. How important do you consider the following possible implementation hurdles of RFID in the retail industry? (scale: 1-5, very unimportant - very important)
a. Complex data management
b. Frequency issues
c. Poor integration in the company (little support from executives/employees)
d. Negative network effects
e. Technological issues
f. High costs (initial + maintenance)
g. Others (please specify):
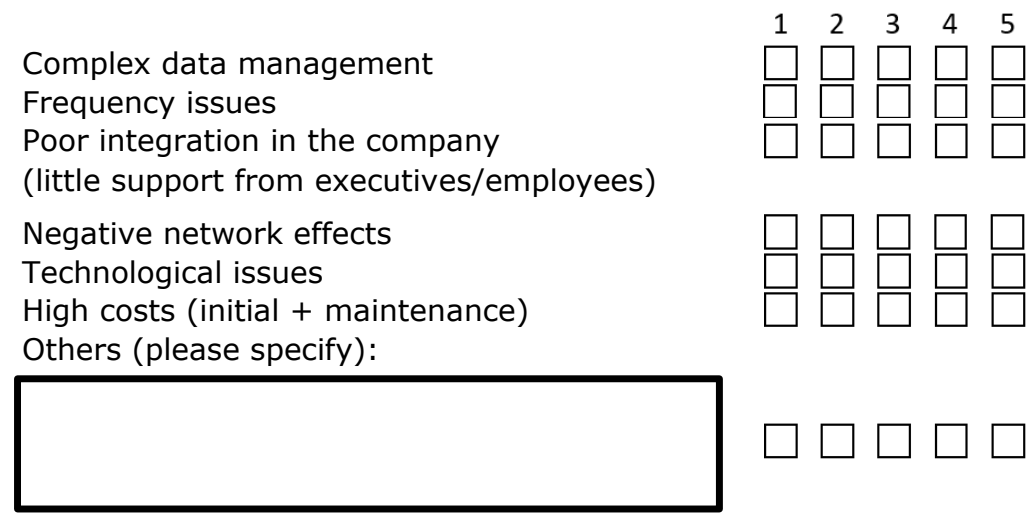

2. Why did you rate the highest rated item(s) as most important? What makes it (them) more important than the others?

3. Why do you consider the lowest rated item(s) less important than the others?

4. How could the highest ranked item keep RFID from harvesting its full potential in the long run? Which other items have severe negative implications in the long-run? 
5. In previous studies, the main technological issue was considered the decreased scanning accuracy of packages that contain liquids or metal.

a. Are there other, equally important technological issues?

. Is there already a solution to this issue? If not, do you think that this problem will be solved in the next 5-10 years?

6. What actions could be taken to overcome the issues?

7. How important do you consider the following possible benefits of RFID in the retail industry? (scale: 1-5, very unimportant - very important)

a. Precise inventory management

i. Decrease unnecessary manual orders

ii. Reduce out-of-stock items

b. Traceability of the product throughout the supply chain

c. More efficient material handling

d. Exact cost determination of sold items

e. Faster product receipt verification

f. Others (please specify):

8. Why did you rate the highest rated item(s) as most important? What makes it (them) more important than the others? 
9. Why do you consider the lowest rated item(s) less important than the others?

10. Do you think that generally the benefits of RFID outweigh the problems? In what way do they / do they not?

11. Additional comments/remarks: 